\title{
Fontes de Energia em Suplementos Múltiplos de Auto-Regulação de Consumo na Recria de Novilhos Mestiços em Pastagens de Brachiaria decumbens durante o Período das Águas
}

\author{
Mário Fonseca Paulino ${ }^{1}$, Eduardo Henrique Bevitori Kling de Moraes², Joanis Tilemahos \\ Zervoudakis $^{3}$, Emerson Alexandrino ${ }^{4}$, Darcilene Maria de Figueiredo ${ }^{2}$
}

\begin{abstract}
RESUMO - Objetivou-se avaliar o efeito de diferentes fontes energéticas em suplementos múltiplos de auto-regulação de consumo sobre o ganho médio diário (GMD), ganho de peso total (GPT), pH e a concentração de amônia ruminal em novilhos recriados em pastejo no período das águas. Foram avaliados suplementos contendo grão de milho moído (GMM), milho desintegrado com palha e sabugo (MDPS), sorgo moído (SM) e tratamento controle (mistura mineral - MM). Utilizaram-se 16 novilhos mestiços Holandês-Zebu, nãocastrados, com 12 meses de idade e peso médio inicial de $265 \mathrm{~kg}$ para avaliar o desempenho. Os parâmetros ruminais foram obtidos utilizando-se quatro novilhos mestiços Holandês-Zebu fistulados no rúmen. $\mathrm{O}$ pH do líquido ruminal variou de 6,43 a 6,62 (média de 6,55), não sendo influenciado pelas quantidades de sal e de suplemento consumidas. As concentrações de amônia foram de 9,61; 25,71; 24,45 e 26,04 mg/dL, respectivamente para os tratamentos MM, GMM, MDPS, SM. Não se verificou diferença entre os tratamentos, contudo o suplemento MDPS proporcionou ganhos adicionais em torno de $220 \mathrm{~g} / \mathrm{animal} / \mathrm{dia}$. Maiores concentrações de amônia ruminal foram observadas nos animais suplementados.
\end{abstract}

Palavras-chave: auto-controle, bovino de corte, energia, suplementação, uréia

\section{Energy Sources in Multiple Supplements of Self-Feed of Growing Crossbred Steers at Pastures of Brachiaria Decumbens in Wet Season}

\begin{abstract}
The effect of different energy sources in multiple supplements of self-feed on the average daily gain (ADG), total weight gain (TWG), pH and ruminal ammonia concentration of steers grazed at pasture in the wet season was evaluated. Treatments were supplements containing ground corn grain (GCG), corn, ears and cob (CEC), ground sorghum (GS) and control treatment (mineral mix - MM). Sixteen crossbreed steers with initial age and weight of 12 months old and $265 \mathrm{~kg}$ were used. Ruminal parameters were obtained from four crossbreed steers fistulated in the rumen. The $\mathrm{pH}$ values ranged from 6.43 to 6.62 , with an average of 6.55 not having effect for the amounts of salt and supplement consumed. Concentrations were 9.61, 25.71, 24.45 and 26.04 mg/dL, respectively, for MM, GCG, CEC and GS treatments. It was not found differences between treatments, although the supplement CEC provided additional gains of $220 \mathrm{~g} / \mathrm{animal} / \mathrm{day}$. Higher concentrations of ruminal ammonia were observed in the supplemented animals.
\end{abstract}

Key Words: beef cattle, energy, self-feed, supplementation, urea

\section{Introdução}

Níveis adequados de desempenho animal nem sempre são alcançados quando a forragem é consumida como única fonte de alimento. Portanto, o aumento no ganho de peso de bovinos consumindo forragens com conteúdo moderado de proteína pode requerer o uso de suplementação energética (Hess et al., 1996).

Suplementos energéticos geralmente possuem maior coeficiente de digestibilidade da matéria seca (MS) que as forragens, de modo que o fornecimento destes suplementos geralmente melhora o coeficiente de digestibilidade da MS da dieta total. Contudo, a extensão desta melhoria depende da proporção de suplementos energéticos na dieta, da digestibilidade da MS da forragem e do suplemento e principalmente do efeito do suplemento sobre a atividade dos microrganismos do rúmen.

As concentrações de nitrogênio amoniacal (N$\mathrm{NH}_{3}$ ) podem ser reduzidas e o fluxo de nitrogênio não-amoniacal para o duodeno pode ser elevado quando animais que consomem pasto são suplementados com carboidratos não-estruturais (CNE) (Van Vuuren et al. 1990). O enfoque central da questão é evitar que

\footnotetext{
${ }_{1}$ Professor do DZO, UFV, Pesquisador do CNPq, Viçosa-MG, 36570-000.

2 Zootecnista, MS, Estudante de Doutorado, DZO/UFV, Viçosa-MG - Bolsista do CNPq.

3 Zootecnista, D.Sc., Professor Adjunto, Universidade Federal do Mato Grosso-UFMT, Cuiabá-MT.

${ }^{4}$ Professor Adjunto de Nutrição e Pastagem do Departamento de Agronomia, Universidade Federal de Rondônia, Campus de Rolim de Moura, Avenida Norte Sul, 7300, Bairro Nova Morada, Rolim de Moura, Rondônia, CEP: 78987-000.
} 
haja efeito associativo negativo entre a forragem e os suplementos energéticos. Quando a forragem é de qualidade média ou boa, o fornecimento de suplementos ricos em energia pode gerar um tipo de interação com os microrganismos que induz um efeito negativo sobre o desaparecimento da fibra (Dixon \& Stockdale, 1999). Portanto, o atendimento das necessidades totais de proteína degradada no rúmen deve ser avaliado.

Os custos diários com a distribuição e o transporte de suplementos são bastante significativos. Assim, a formulação de suplementos de auto-regulação de consumo, em que o próprio animal controla seu consumo, surge como excelente ferramenta de manejo em programas de suplementação de ruminantes a pasto, podendo reduzir os gastos com mão-de-obra e transporte e evitando que o animal crie dependência pelo suplemento, apresentando aspectos positivos sob o ponto de vista nutricional, como sincronização de energia-amônia, equilíbrio de $\mathrm{pH}$ e amônia, entre outros (Paulino et al., 2001). No entanto, quando se formula suplementos de auto-regulação de consumo, deve-se assegurar que o consumo dos animais será mantido em níveis desejados para prover nutrientes suplementares e satisfazer suas exigências nutricionais (Bowman e Sowell, 1997).

A uréia e o cloreto de sódio têm sido os principais limitadores de consumo utilizados na formulação de suplementos múltiplos com auto-regulação de consumo (Paulino et al., 2000). Paulino et al. (1983) verificaram a eficiência de altos níveis de uréia em suplementos em permitir aos animais baixo consumo de suplemento.

Objetivou-se, neste estudo, avaliar a influência dos suplementos múltiplos de auto-regulação de consumo formulados com diferentes fontes de energia sobre o desempenho e os parâmetros ruminais de novilhos mestiços recriados em pastejo no período das águas.

\section{Material e Métodos}

O experimento foi conduzido na Central de Experimentação, Pesquisa e Extensão do TriânguloCEPET/UFV, localizada em Capinópolis-MG, durante o período das águas, entre os meses de novembro de 2001 a janeiro de 2002 .

A área experimental constituiu-se de quatro piquetes de 1,5 ha de Brachiaria decumbens Stapf e providos de bebedouros e cochos.

Avaliaram-se suplementos constituídos de uréia, mistura mineral (MM) e grão de milho moído (GMM) ou milho desintegrado com palha e sabugo (MDPS) ou sorgo moído (SM) (Tabela 1), fornecidos em sistema de auto-regulação de consumo. Paralelamente, foi avaliado o tratamento controle (MM), objetivando avaliar o desempenho dos animais que não foram submetidos à suplementação.

Tabela 1 - Composição dos suplementos (\%), com base na matéria natural Table 1 - Composition of supplements, as-fed basis

\begin{tabular}{|c|c|c|c|c|}
\hline \multirow{2}{*}{ Item } & \multicolumn{4}{|c|}{$\begin{array}{c}\text { Tratamento } \\
\text { Treatment }\end{array}$} \\
\hline & $\begin{array}{c}\mathrm{MM}^{1} \\
M M\end{array}$ & $\begin{array}{c}\mathrm{GMM}^{2} \\
G C G\end{array}$ & $\begin{array}{c}\mathrm{MDPS}^{3} \\
C E C\end{array}$ & $\begin{array}{c}\mathrm{SM}^{4} \\
G S\end{array}$ \\
\hline $\begin{array}{l}\text { Mistura mineral }^{5} \\
\text { Mineral mix }\end{array}$ & 100,00 & 12,50 & 12,50 & 12,50 \\
\hline $\begin{array}{l}\text { Uréia/SA }(9: 1)^{6} \\
\text { Urea/AS }\end{array}$ & - & 12,50 & 12,50 & 12,50 \\
\hline $\begin{array}{l}\text { MDPS } \\
\text { Corn, ears and cob }\end{array}$ & - & - & 75,00 & - \\
\hline $\begin{array}{l}\text { Sorgo moído } \\
\text { Ground sorghum }\end{array}$ & - & - & - & 75,00 \\
\hline
\end{tabular}

${ }^{1}$ Mistura mineral; ${ }^{2}$ Grão de milho moído; ${ }^{3}$ Milho desintegrado com palha e sabugo; ${ }^{4}$ Sorgo moído; ${ }^{5}$ Composição percentual: fosfato bicálcico, 50,00; cloreto de sódio, 44,15; sulfato de zinco, 1,50; sulfato de cobre, 0,75 ; sulfato de cobalto, 0,05 ; iodato de potássio, 0,05 e sulfato de magnésio: 0,5 . ${ }^{6}$ Uréia/Sulfato de amônia (9:1).

${ }^{1}$ Mineral mix; ${ }^{2}$ Ground corn grain ${ }^{3}$ Corn, ears and cob; ${ }^{4}$ Ground sorghum ${ }^{5}$ Percentage composition: dicalcium phosfate, 50.00; sodium chloride, $44.15 ;$ zinc sulfate, 1.50; copper sulfate, 0.75; cobalt sulfate 0.05; potassium iodate, 0.05; and magnesium sulfate. ${ }^{6}$ Urea/Ammonia sulfate (9:1). 
Foram utilizados 16 novilhos mestiços HolandêsZebu, não castrados, com 12 meses de idade e peso médio inicial de $265 \mathrm{~kg}$, respectivamente, que foram pesados no início e final do experimento após serem submetidos a jejum de sólidos e líquidos de 18 horas. Os animais foram rotacionados entre os piquetes a cada sete dias visando reduzir os possíveis efeitos de disponibilidades de MS nos piquetes experimentais. As pesagens dos animais, para avaliação do desempenho, foram realizadas a cada 28 dias experimentais.

No primeiro dia de cada período experimental, foi realizada a coleta de pastagem, para determinação da disponibilidade total de matéria seca/ha, efetuandose o corte a $10 \mathrm{~cm}$ do solo de cinco áreas delimitadas por um quadrado metálico de $0,5 \times 0,5 \mathrm{~m}$, escolhidas aleatoriamente em cada piquete experimental (McMeniman, 1997). As amostras foram secas em estufa de ventilação forçada, por 72 horas, e, posteriormente, foram processadas em moinho com peneira com malha de $1,0 \mathrm{~mm}$ e acondicionadas em potes de plástico.

Foram determinados os teores de matéria seca (MS), nitrogênio total (N), extrato etéreo (EE) e cinzas de acordo com Silva \& Queiroz (2002), e fibra em detergente neutro (FDN), segundo Van Soest et al. (1991). Os carboidratos totais (CT) foram obtidos pela equação: 100 - (\%PB + \%EE + \%Cinzas) (Sniffen et al., 1992) e os carboidratos não-fibrosos (CNF), pela diferença entre CT e FDN.

Utilizaram-se quatro animais castrados Holandês-Zebu fistulados no rúmen, com peso médio de $435 \mathrm{~kg}$, para avaliação do $\mathrm{pH}$ e quantificação da concentração de amônia no rúmen. As leituras de $\mathrm{pH}$ foram realizadas com auxílio de um peagâmetro digital logo após a coleta do líquido ruminal. Para a determinação das concentração de amônia, coletaram-se $50 \mathrm{~mL}$ de líquido ruminal, que foram fixados com $1,0 \mathrm{~mL}$ de $\mathrm{H}_{2} \mathrm{SO}_{4}(1: 1)$ e congelados a $-20^{\circ} \mathrm{C}$. As concentrações do $\mathrm{N}$ amoniacal foram obtidas após destilação com KOH 2N, segundo técnica descrita por Fenner, em 1965, adaptada por Vieira (1980).

Empregou-se o delineamento inteiramente casualizado para avaliar o desempenho produtivo dos animais. Os animais fistulados foram distribuídos em delineamento quadrado latino, com quatro tratamentos e quatro períodos experimentais. Utilizou-se o Sistema de Análises Estatísticas e Genéticas - SAEG (UFV, 2000) na análise dos resultados, adotando-se o teste de Student Newman-Keuls (SNK) a 5\% de probabilidade para comparar as médias observadas.

\section{Resultados e Discussão}

A disponibilidade média de matéria seca das pastagens durante o período experimental foi de $4.000 \mathrm{~kg} / \mathrm{ha}$, o que propiciou condições satisfatórias para que os animais exercessem o pastejo seletivo. A composição bromatológica das amostras de pastagem coletadas via simulação manual de pastejo e dos suplementos encontra-se na Tabela 2.

Os dados referentes aos ganhos médios diários (GMD) e ao ganho de peso total (GPT) e aos consumos médios dos suplementos são expressos na Tabela 3 .

O consumo médio diário dos suplementos foi de, aproximadamente, $0,525 \mathrm{~kg} / \mathrm{animal}$, ou seja, $0,2 \%$ do $\mathrm{PV}$, o que demonstra a eficácia dos níveis de $12,5 \%$ de mistura mineral e $12,5 \%$ de uréia contidos nos suplementos em manter o consumo dos suplementos próximos aos $0,500 \mathrm{~kg} / \mathrm{dia}$, preconizados durante a formulação do suplemento.

A forragem disponível caracterizou-se como de boa qualidade (Tabela 2), propiciando bom desempenho aos animais não submetidos à suplementação. $\mathrm{O}$ ganho médio observado foi superior aos $0,931 \mathrm{~kg} / \mathrm{dia}$ observados por Acedo et al. (2003) em bovinos na fase de recria em pasto de Brachiaria decumbens durante os períodos de seca-águas e águas.

De acordo com Caton e Dhuyvetter (1997), em algumas gramíneas, a produção de $\mathrm{N}$ microbiano pelos microganismos ruminais pode ser limitado pelo suprimento de substratos prontamente fermentecíveis. Desse modo, a suplementação com pequenas quantidades de grãos poderia ser benéfica por aumentar o $\mathrm{N}$ microbiano que alcança o intestino, melhorando o desempenho animal. Embora não tenha sido verificada diferença estatística para o desempenho dos animais submetidos aos diferentes tratamentos, constatou-se superioridade numérica no ganho médio diário dos bovinos suplementados (em média 15\%) quando comparado aos animais não suplementados.

Neste contexto, o suplemento MDPS proporcionou ganhos adicionais em torno de 220 g/animal/dia, em relação ao tratamento controle, o que pode estar associado à eliminação dos efeitos associativos negativos entre forragem e grãos, proporcionados pelo atendimento total das exigências de proteína degradada no rúmen.

Frente aos resultados obtidos, torna-se importante a caracterização das diferentes fontes energéticas, principalmente no tocante às taxas de degradação, que juntamente com os custos devem ser considera- 
Tabela 2 - Teores médios de meteria seca (MS\%), matéria orgânica (MO), proteína bruta (PB), extrato etéreo (EE), cinzas, carboidratos totais (CT), fibra em detergente neutro (FDN) e carboidratos não-fibrosos (CNF) da $B$. decumbens e dos suplementos

Table 2 - Average content s of dry matter (DM\%), organic matter (OM), crude protein (CP), ether extract (EE), ash, total carbohydrates (TC), neutral detergent fiber (NDF) and nonfiber carbohydrates (NFC) of B. decumbens and supplements

\begin{tabular}{|c|c|c|c|c|c|}
\hline \multirow{2}{*}{ Item } & \multicolumn{4}{|c|}{$\begin{array}{c}\text { Tratamento } \\
\text { Treatment }\end{array}$} & \multirow{2}{*}{ B.decumbens ${ }^{5}$} \\
\hline & $\begin{array}{c}\mathrm{MM}^{1} \\
M M \\
\end{array}$ & $\begin{array}{l}\mathrm{GMM}^{2} \\
G C G \\
\end{array}$ & $\begin{array}{c}\text { MDPS }^{3} \\
\text { CEC }\end{array}$ & $\begin{array}{l}\mathrm{SO}^{4} \\
S M C\end{array}$ & \\
\hline $\begin{array}{l}\text { MS (\%) } \\
S M C\end{array}$ & 98,70 & 90,94 & 90,40 & 89,90 & 23,25 \\
\hline $\mathrm{MO}^{6}$ & - & 98,92 & 98,71 & 98,82 & 93,02 \\
\hline $\begin{array}{l}O M \\
\mathrm{~PB}^{6}\end{array}$ & - & 41,17 & 41,10 & 42,40 & 11,71 \\
\hline $\begin{array}{l}C P \\
\mathrm{EE}^{6} \\
E E\end{array}$ & - & 4,71 & 3,74 & 2,96 & 1,25 \\
\hline $\begin{array}{l}\text { Cinzas } \\
\text { Ash }\end{array}$ & - & 1,08 & 1,29 & 1,18 & 6,98 \\
\hline $\begin{array}{l}\mathrm{CT}^{6} \\
T C\end{array}$ & - & 53,04 & 54,87 & 53,46 & 80,06 \\
\hline $\begin{array}{l}\mathrm{FDN}^{6} \\
N D F\end{array}$ & - & 11,30 & 28,15 & 9,95 & 66,22 \\
\hline $\begin{array}{l}\mathrm{CNF}^{6} \\
\mathrm{NFC}\end{array}$ & - & 41,74 & 26,72 & 43,51 & 13,84 \\
\hline
\end{tabular}

${ }^{1}$ Mistura mineral; ${ }^{2}$ Grão de milho moído; ${ }^{3}$ Milho desintegrado com palha e sabugo; ${ }^{4}$ Sorgo moído; ${ }^{5}$ Simulação manual de pastejo; ${ }^{6} \%$ MS.

${ }^{1}$ Mineral mix; ${ }^{2}$ Ground corn grain; ${ }^{3}$ Corn, ears and cob; ${ }^{4}$ Ground sorghum; ${ }^{5}$ Hand plucking sample; $6 \%$ DM.

Tabela 3 - Pesos vivo inicial (PVI - kg) e final (PVF - kg), ganho de peso total (GPT- kg), ganho médio diário (GMD - kg/ dia), rendimento de carcaça fria (RCF- \%) e consumo de suplemento ( $/$ /dia) para os diferentes tratamentos

Table 3 - Initial (ILW - kg) and final (FLW - kg) live weight, total gain (TG - kg), average daily (ADG - g/day), carcass yield (CY - \%) and supplement intake (g/day) for the different treatments

\begin{tabular}{|c|c|c|c|c|c|}
\hline \multirow{2}{*}{ Item } & \multicolumn{4}{|c|}{$\begin{array}{l}\text { Tratamento } \\
\text { Treatment } \\
\end{array}$} & \multirow{2}{*}{$\mathrm{CV}(\%)$} \\
\hline & $\begin{array}{c}\mathrm{MM}^{1} \\
M M \\
\end{array}$ & $\begin{array}{l}\mathrm{GMM}^{2} \\
G C G\end{array}$ & $\begin{array}{l}\mathrm{MDPS}^{3} \\
D C S C\end{array}$ & $\begin{array}{c}\mathrm{SM}^{4} \\
G S\end{array}$ & \\
\hline $\begin{array}{l}\text { PVI } \\
\text { ILW }\end{array}$ & 265,00 & 270,00 & 265,50 & 265,50 & - \\
\hline $\begin{array}{l}\text { PVF } \\
F L W\end{array}$ & 362,25 & 378,50 & 381,75 & 362,75 & - \\
\hline $\begin{array}{l}\mathrm{GPT}^{5} \\
T G\end{array}$ & 97,25 & 108,50 & 116,25 & 107,25 & 12,81 \\
\hline $\begin{array}{l}\mathrm{GMD}^{5} \\
A D G\end{array}$ & 1,16 & 1,29 & 1,38 & 1,16 & 12,81 \\
\hline $\begin{array}{l}\text { Consumo suplemento (g/dia) } \\
\text { Supplement intake (g/day) }\end{array}$ & 79 & 491 & 519 & 567 & - \\
\hline
\end{tabular}

${ }^{1}$ Mistura mineral; ${ }^{2}$ Grão de milho moído; ${ }^{3}$ Milho desintegrado com palha e sabugo; ${ }^{4}$ Sorgo moído; ${ }^{5}$ Efeito relativo a tratamento não-significativo pelo teste SNK $(P>0,05)$.

${ }^{1}$ Mineral mix; ${ }^{2}$ Ground corn grain; ${ }^{3}$ Corn, ears and cob; ${ }^{4}$ Ground sorghum; 5 Relative effect to treatment not significant $(P>.05)$ by SNK test.

dos na seleção dos ingredientes a serem fornecidos para bovinos em pastejo no período das águas.

Os ganhos adicionais obtidos com a suplementação no período das águas devem ser avaliados dentro do enfoque de pecuária de ciclo curto (Paulino et al., 2002). Neste sentido, quando se utiliza suplementação energética em animais mantidos em pastagens que ainda tem qualidade, é necessário que se pondere sobre o sistema produtivo como um todo, sobre o possível aumento na taxa de lotação, produção por área, giro de capital e redução de animais em estoque. 
$\mathrm{Na}$ Tabela 4, são apresentados os valores de pH e as concentrações de amônia ruminal. A análise do pH não demonstrou efeitos significativos para os suplementos utilizados. Os valores observados encontram-se na faixa de 6,43 a 6,62 , que estão na faixa de $\mathrm{pH}$ para o máximo crescimento microbiano (Hoover, 1986). Valores de $\mathrm{pH}$ inferiores a 6,0 podem acarretar diminuição das atividades das bactérias fibrolíticas, diminuindo, conseqüentemente, a degradação da fibra (Coelho da Silva \& Leão, 1979).

A concentração de amônia ruminal do tratamento controle foi menor $(\mathrm{P}<0,05)$ que a observada nos animais suplementados que não diferiram entre si, em decorrência da alta taxa de hidrólise da uréia presente nos suplementos, demonstrando o fornecimento de uma fonte prontamente disponível de $\mathrm{N}$ para os microrganismos. Os valores médios encontrados em cada tratamento estão acima do valor considerado por Satter \& Slyter (1974) como limitante da fermentação ruminal $\left(5 \mathrm{mg} / \mathrm{L}\right.$ de $\mathrm{N}-\mathrm{NH}_{3}$ ), indicando, desta forma, que a amônia ruminal não limitou o crescimento microbiano em nenhum dos tratamentos. No entanto, apenas nos animais suplementados, estas concentrações foram superiores aos 23,0 mg/dL de líquido ruminal recomendados por Mehrez et al. (1977) como ideais para a maximização da taxa de fermentação ruminal.

Tabela 4 - Médias e coeficiente de variação (CV) obtidos para pH e concentrações de $\mathrm{N}-\mathrm{NH}_{3}$ (mg/dL de líquido ruminal) para os diferentes tratamentos

Table 4 - Means, coefficient of variation (CV) for $\mathrm{pH}$ and $\mathrm{N}-\mathrm{NH}_{3}$ concentrations ( $\mathrm{mg} / \mathrm{dL}$ in ruminal liquid) for the different treatments

\begin{tabular}{lccccc}
\hline \multicolumn{5}{c}{$\begin{array}{c}\text { Tratamento } \\
\text { Treatment }\end{array}$} & \multirow{2}{*}{ CV $(\%)$} \\
\cline { 2 - 5 } Item & $\mathrm{MM}^{1}$ & $\mathrm{GMM}^{2}$ & MDPS $^{3}$ & SM $^{4}$ & \\
& $M M$ & $G C G$ & $D C S C$ & $G S$ & 1,89 \\
$\mathrm{PH}$ & 6,55 & 6,43 & 6,62 & 6,59 & 5,98 \\
\hline
\end{tabular}

${ }^{1}$ Mistura mineral; ${ }^{2}$ Grão de milho moído; ${ }^{3}$ Milho desintegrado com palha e sabugo; ${ }^{4}$ Sorgo moído; 5 Efeito relativo a tratamento não significativo pelo teste SNK $(P>0,05)$

${ }^{1}$ Mineral mix; ${ }^{2}$ Ground corn grain; ${ }^{3}$ Corn, ears and cob; ${ }^{4}$ Ground sorghum; ${ }^{5}$ Relative effect to treatment not significant $(P>.05)$ by SNK test.

Para a otimização do crescimento bacteriano e maximização da degradação da fibra, propiciando maiores consumos de MS, deve-se procurar o sinergismo entre os valores de $\mathrm{pH}$ e amônia ruminal. Esta observação torna-se evidente quando observados os animais suplementados que, em média, apresentaram valores adequados de $\mathrm{pH}(6,55)$ e concentrações de amônia $(25,4 \mathrm{mg} / \mathrm{dL})$ acima do valor mínimo considerado ideal para otimizar a degradação da fibra. Neste sentido, estes parâmetros favoráveis poderiam possibilitar maior consumo de MS pelos animais suplementados.

\section{Conclusões}

A suplementação, no período das águas, com suplementos múltiplos não apresentou diferença significativa para o desempenho dos animais. No entanto, constatou-se superioridade numérica (em média $15 \%$ ) em termos de ganho médio diário para os bovinos suplementados.
$\mathrm{O} \mathrm{pH}$ do líquido ruminal não foi influenciado pelas quantidades de sal e suplemento consumidos, entretanto, maiores concentrações de amônia ruminal foram observadas nos animais suplementados.

\section{Literatura Citada}

ACEDO, T.S.; PAULINO, M.F.; VALADARES FILHO, S.C. et al. Diferentes fontes protéicas em suplementos múltiplos de baixo consumo para recria de novilhos no período de transição seca-águas e águas. In: REUNIÃO ANUAL DA SOCIEDADE BRASILEIRA DE ZOOTECNIA, 40, Santa Maria, 2003. Anais... Santa Maria: SBZ (CD-ROM, Nutrição de Ruminantes).

BOWMAN, J.G.P.; SOWELL, B.F. Delivery method and supplement consumption by grazing ruminants: A review. Journal of Animal Science, v.75, p.543-549, 1997.

CATON, J.S.; DHUYVETTER, D.V. Influence of energy supplementation on grazing ruminants: requirements and responses. Journal of Animal Science, v.75, n.2, p.533542, 1997.

COELHO DA SILVA, J.F.; LEÃO, M.I. Fundamentos de nutrição dos ruminantes. Piracicaba: Livroceres, 1979. 380p.

DIXON, R.M.; STOCKDALE, C.R. Associative effects between forages and grains: consequences for feed utilization. 
Australian Journal Agricultural Research, v.50, n.5, p.757-773, 1999.

HESS, B.W.; KRYSL, L.J.; JUDKINS, M.B. et al. Supplemental cracked corn or wheat bran for steers grazing Endophyte-Free fescue pasture: effects on live weight gain, nutrient quality, forage intake, particulate and fluid kinetics, ruminal fermentation, and digestion. Journal Animal Science, v.74, p.116-1125, 1996.

HOOVER, W.H. Chemical factors involved in ruminal fiber digestion. Journal of Dairy Science, v.69, n.10, p.27552766, 1986

McMENIMAN, N.P. Methods of estimating intake of grazing animals. In: REUNIÃO ANUAL DA SOCIEDADE BRASILEIRA DE ZOOTECNIA, 34., 1997, Juiz de Fora. Anais... Juiz de Fora: Sociedade Brasileira de Zootecnia, 1997. p.131-168.

MEHREZ, A.Z.; ØRSKOV, E.R.; McDONALD, I. Rates of rumem fermentation in relation to ammonia concentration. British Journal of Nutrition, v.38, n.3, p.437-443, 1977.

PAULINO, M.F. Suplementação de bovinos em pastejo. Informe Agropecuário, v.21, n.205, p.96-106, 2000.

PAULINO, M.F.; DETMANN, E.; ZERVOUDAKIS, J.T. Suplementos múltiplos para recria e engorda de bovinos em pastejo. In: SIMPÓSIO DE PRODUÇÃO DE GADO DE CORTE, 2., 2001, Viçosa, MG. Anais... Viçosa, MG: SIMCORTE, 2001. p.187-231.

PAULINO, M.F.; RUAS, J.R.M.; REHFELD, O.A.M. et al. Efeitos de diferentes níveis de uréia sobre o desenvolvimento de novilhas zebu. Arquivo Brasileiro de Medicina Veterinária e Zootecnia, v.35, p.231-245, 1983.

PAULINO, M.F.; ZERVOUDAKIS, J.T.; MORAES, E.H.B.K. et al. Bovinocultura de ciclo curto em pastagens. In: SIMPÓSIO DE PRODUÇÃO DE GADO DE CORTE, 3., 2002, Viçosa, MG. Anais... Viçosa, MG: SIMCORTE, 2002. p.153-196.
SATTER, L.D.; SLYTER, L.L. Efect of ammonia concentration on rumen microbial protein in vitro. British Journal of Nutrition, v.32, n.2, p.199-208, 1974.

SILVA, D.J.; QUEIROZ, A.C. Análise de alimentos: métodos químicos e biológicos. 3.ed. Viçosa, MG: Universidade Federal de Viçosa, 2002. 165p.

SNIFFEN, C.J.; O'CONNOR, J.D.; Van SOEST, P.J. et al. A net carbohydrate and protein system for evaluating cattle diets: II. Carbohydrate and protein availability. Journal of Animal Science, v.70, n.11, p.3562-3577, 1992.

UNIVERSIDADE FEDERAL DE VIÇOSA - SAEG, UFV. Sistema de análises estatísticas e genéticas. Versão 8.1. Viçosa, MG: 2000. (Manual do usuário).

Van SOEST, P.J.; ROBERTSON, J.B.; LEWIS, B.A. Methods for dietary fiber, and nonstarch polysaccharides in relation to animal nutrition. Journal of Dairy Science, v.74, n.10, p.3583-3597, 1991.

Van VUUREN, A.M.; TAMMINGA, S. KETELAAR, R.S. Ruminal availability of nitrogen and carbohydrates from fresh and preserved herbage in dairy cows. Netherlands Journal Agricultural Science, v.38, p.499-512, 1990.

VIEIRA, P.F. Efeito do formaldeído na proteção de proteínas e lipídeos em rações de ruminantes. Viçosa, MG: Universidade Federal de Viçosa, 1980. 98p. Tese (Doutorado em Zootecnia) - Universidade Federal de Viçosa, 1980.

Recebido em: 22/04/04 Aceito em: 17/11/04 